\title{
DISTORTION MODELLING OF STEEL 316L SYMMETRIC BASE PLATE FOR ADDITIVE MANUFACTURING PROCESS AND EXPERIMENTAL CALIBRATION
}

\author{
Abhilash KIRAN *, Josef HODEK, Jaroslav VAVŘíK, Ondřej LUKÁŠ, Miroslav URBÁNEK \\ COMTES FHT a.s., Průmyslová 995, Dobřany, Czech Republic, EU, abhilash.kiran@comtesfht.cz
}

https://doi.org/10.37904/metal.2020.3565

\begin{abstract}
Distortion in additively manufactured metal parts is of interest to keep structural reliability. It is important to control the dimensional tolerance of the additively manufactured structure. This does not only reduce the cost of manufacturing, but also improves the quality of the manufactured parts. Distortion in additive manufacturing (AM) is inevitable due to localized heating, large thermal gradient, thermal cycles, cooling rate, process parameters, etc. Base plate distortion during the AM process was studied in detail. Base plate structural deformation was measured using a 3D scanner. The surface geometry of the base plate reveals a large distortion beneath the deposited material due to the temperature gradient. Thermal history and distortion during the AM process were classified into three stages. Mitigation methods for the respective stage was discussed. A Finite Element Model (FEM) was built and a numerical calculation for thermal and distortion was validated to experimental results.
\end{abstract}

Keywords: Additive manufacturing, direct energy deposition (DED), finite element modeling, distortion, steel $316 \mathrm{~L}$

\section{INTRODUCTION}

Direct Energy Deposition (DED) is one of the well-known metal deposition techniques in the Additive Manufacturing (AM) process. DED process utilizes a focused heat source (Laser or Electron beam) to melt feedstock material in the form of powder or wire to build a three-dimensional structure [1]. The feedstock is provided coaxially to laser at the melt pool. DED exhibits key advantages such as support less deposition with high production rate, development of functionally graded materials, etc. The localized heating source creates large thermal gradients that result in residual stress and distortion in the sample. A unique application of DED in the field of repairing functional metal parts, surface treatment, etc. drags attention to analyze building platforms. Distortion in the built platform is important to understand in DED to implement function parts repair applications successfully.

The literature on residual stress and distortion mitigation in the base plate explores several studies [2-7]. David J.Corbin et al. studied preheating thin and thick base plate. The outcome of the research work is preheating effective for the thin base plate. $27.4 \%$ of distortion reduction is reported for thin substrate during first layer deposition. However, the number of deposition layers was limited to three and ten layers. Xufei Lu et al. studied the process parameter influence on asymmetric base plate distortion. The base plate was mounted in the form of a cantilever structure. Distortion during the deposition of the first layer and during the cooling stage after deposition contributes a significate percentage for total distortion of the base plate. Preheating base plate reduces the temperature gradient and initial distortion almost vanished at $700^{\circ} \mathrm{C}$. In both cases a structural boundary condition was different and the base plate was not symmetrical which influenced base plate distortion during deposition process.

The primary objective of this work is to develop the FE Model and validate numerical results with experimental data for further application of the numerical model. Another main goal of this work is to study in detail the effect 
of distortion during three-phases of deposition i.e. Phase (1) deposition at the first layer, Phase (2) Deposition from the second layer to end, Phase (3) a cooling period.

\subsection{Materials}

Austenite stainless steel 316L (Sandvik Osprey LTD) powder with a 50-150 $\mu \mathrm{m}$ particle size range was used as deposition material. The base plate cut from $316 \mathrm{~L}$ rolled sheet was heat-treated at $400{ }^{\circ} \mathrm{C}$ for four hours to remove potential residual stress. Chemical properties of steel $316 \mathrm{~L}$ are listed in Table 1.

Table 1 Powder and base plate steel 316L chemical composition (wt. \%)

\begin{tabular}{|c|c|c|c|c|c|c|}
\hline & Fe & Cr & Ni & Mo & Mn & Si \\
\hline Powder (316L) & Bal. & 17.2 & 10.4 & 2.3 & 1.3 & 0.8 \\
\hline Base Plate (316L) & Bal. & 16.24 & 10.49 & 2.14 & 1.12 & 0.44 \\
\hline
\end{tabular}

Figure 1 depicts the austenitic steel 316L temperature-dependent material properties used in the numerical analyses. Thermophysical properties were generated in JmatPro software using the chemical properties of the material listed in Table 1.
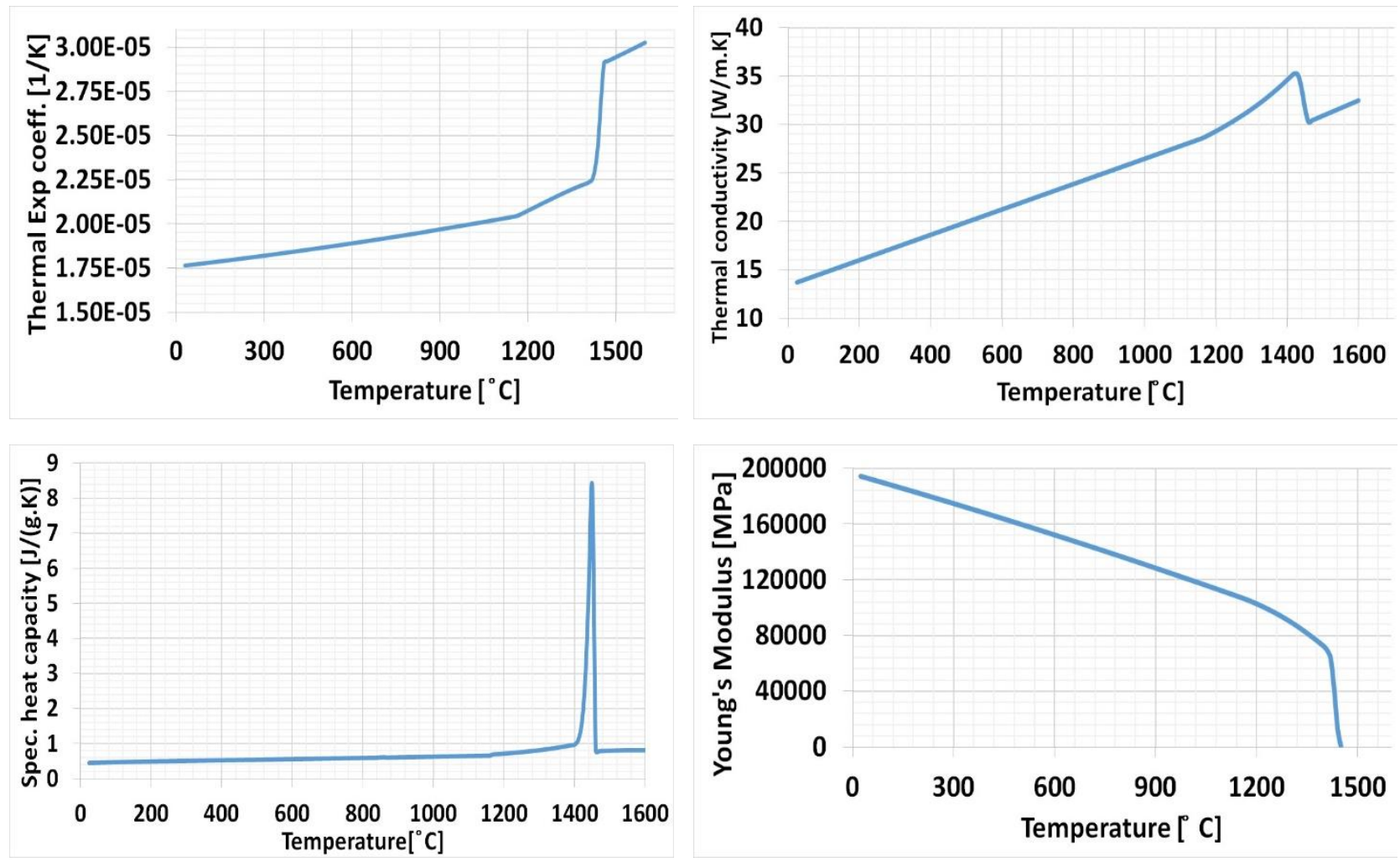

Figure 1 Temperature dependent material properties for FEM simulation

\subsection{Experimental setup and measurement}

InssTek MX-600 metallic deposition system is equipped with DED process technology that was used for the deposition. The machine generates a laser beam with the diameter of $0.8 \mathrm{~mm}$. The laser power was maintained at $500 \mathrm{~W}$. The velocity of the laser head nozzle was $14 \mathrm{~mm} / \mathrm{sec}$. Argon was used as shielding gas during the deposition process. Materialise Magics software was used for job preparation that includes defining scanning strategy, model orientation, define process parameters for the deposition machine. A contour filling scanning strategy was implemented [8]. 
The thermocouple of type ' $K$ ' was used to measure in situ temperature on the base plate [8]. Thermocouple positions and sample dimensions are shown in (Figure 2 a). TC-1 and TC-2 thermocouples are located at the top surface of the base plate in X-Y plane. Thermocouple TC_BC was welded at the centroid of the bottom surface of the base plate. Deposition height is $10 \mathrm{~mm}$ in the Z-axis. The building structure consists of 40 layers. Building time was 130 minutes.

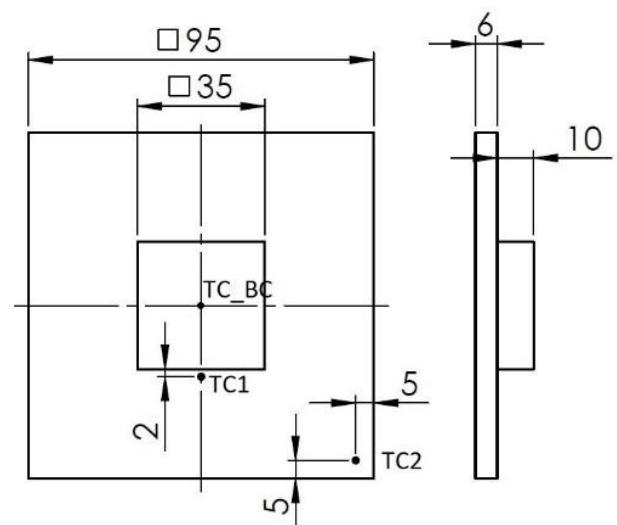

(a)

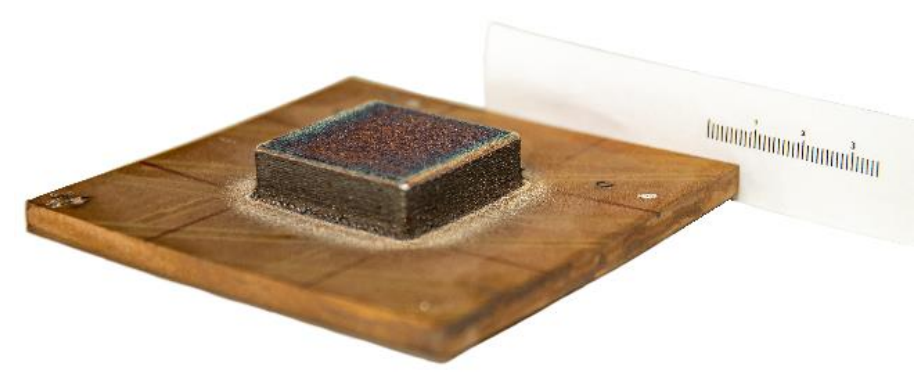

(b)

Figure 2 (a) Model dimension and thermocouple location in $\mathrm{mm}$ (b) 3D printed structure on base plate (scale in $\mathrm{mm}$ )

Distortion was measured using Optical Precision Measuring Machine (OPMM) ATHOS Capsule (GOM Company). The surface geometry of the base plate before the deposition was measured as a reference profile. The surface profile of the deposited model shown in (Figure $\mathbf{2} \mathbf{b}$ ) was generated using OPMM. The reference model was compared to the deposition model using GOM Inspect software for distortion measurement.

\subsection{FE model}

The CAD model was prepared using 3DExperience CATIA software. FE model was prepared using 3DExperience finite element analysis software. 3DExperience dedicated AM module was employed for DED Thermo-mechanical process simulation. Laser path and element activation were defined using G-code from the machine. G-code was translated into a data file using the python script and attached to the AM process simulation. Data included a coordinate position and corresponding time with laser power was formulated in the data file. Heat Transfer Coefficient (HTC) of $18 \mathrm{~W} / \mathrm{m}^{2} . \mathrm{K}$ and emissivity of 0.1 was set to the deposition material. The HTC of $40 \mathrm{~W} / \mathrm{m}^{2} . \mathrm{K}$ was set to the base plate. The absorption coefficient was set to 0.42 . The initial temperature of $27^{\circ} \mathrm{C}$ was allotted for the whole structure. Ambient temperature was set to $27^{\circ} \mathrm{C}$. Hexa dominant elements which contained linear heat transfer element (DC3D8) for thermal analysis were used. Linear elements (C3D8) from the 3DExperience library was used for a structural analysis. FE model consisted of 53016 elements and 63175 nodes on the base plate. The element size in the base plate was $1.011 \times 1.011 \times 1 \mathrm{~mm}$. The deposition structure contained the element of size $1 \times 1 \times 0.5 \mathrm{~mm}$ which results in 25920 elements and 28749 nodes. The thermal analysis was simulated using above stated boundary conditions and time depended thermal development output was linked to the mechanical analysis to drive a nonlinear distortion calculation.

\section{RESULTS AND DISCUSSION}

\subsection{Thermal history}

The thermal history from the FEM calculation at specific nodal positions was compared to corresponding thermocouple locations on the base plate. A significant-close agreement was noticed. 
Three phases of the temperature evolution can be noticed from the thermal history as shown in Figure 3 . The first phase of the temperature evolution was during the deposition of the first layer. A sharp rise in temperature up to $420^{\circ} \mathrm{C}$ from the room temperature at the bottom center of the base plate (TC_BC) was recorded. Similarly, A sharp rise to $200^{\circ} \mathrm{C}$ was recorded from TC2 which was at the upper surface of the base plate about $2 \mathrm{~mm}$ away from the contour deposition path. A remarkable difference in the temperature evolution can be noticed around the deposition and at the bottom surface of the base plate. TC1 which was at the furthest from the deposition recorded temperature rise to $60^{\circ} \mathrm{C}$.

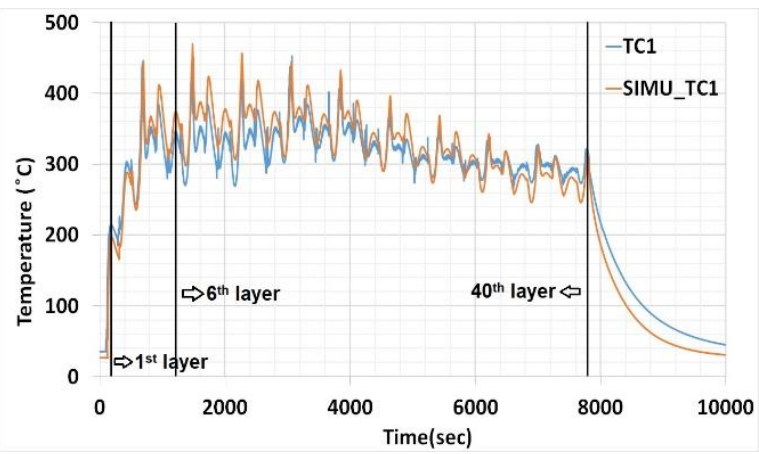

(a)

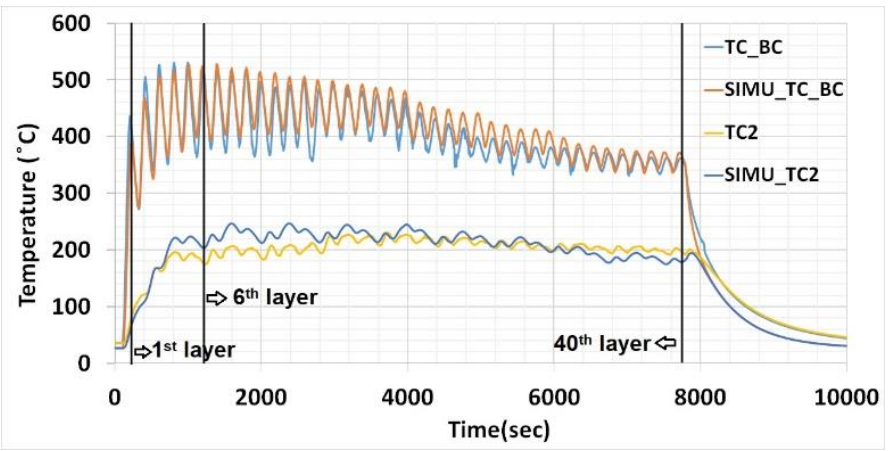

(b)

Figure 3 (a) Thermal history from thermocouple TC1 (b) Thermal history from thermocouples TC2 \& TC_BC

The second phase showed a stable temperature period from the $2^{\text {nd }}$ layer to the $40^{\text {th }}$ layer depicted in (Figure 3). During the third layer deposition, the maximum of $520^{\circ} \mathrm{C}, 440^{\circ} \mathrm{C}$ was recorded from TC_BC, TC1 respectively. Once the highest temperature was reached, gradual temperature drop was recorded for every layer deposition in the case of TC1 and TC_BC as shown in (Figure 3). This is due to the increase in distance of the melt pool from the base plate. The extreme peaks in the graph were recorded when the thermal source approach to the thermocouple. The fluctuation in temperature at these two positions reveals base plate sensitivity to moving concentrated thermal energy under and around the deposition zone. Almost a stable temperature of about $200^{\circ} \mathrm{C}$ was recorded at the TC2 position. This shows a temperature gradient away from the deposition vicinity in the base plate during the deposition process from in situ measurements.

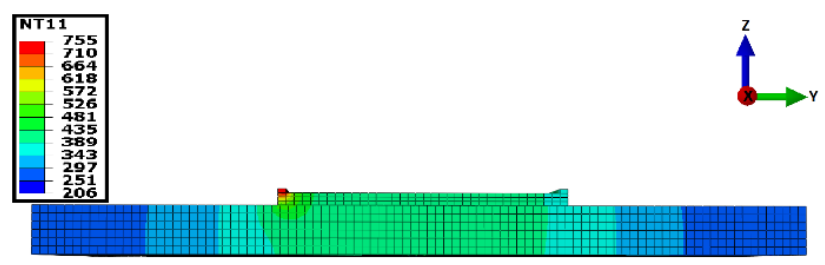

(a)

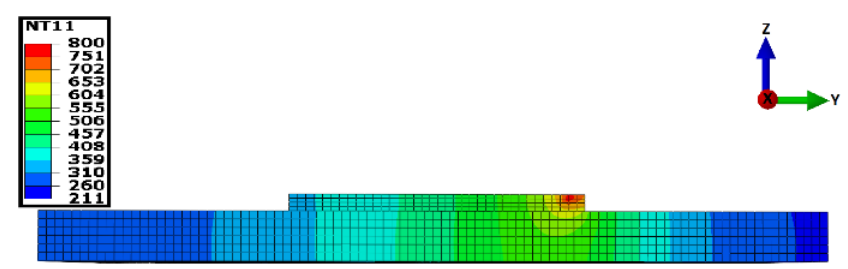

(b)

Figure 4 (a) Thermal evolution at the beginning of the 6 th layer in ${ }^{\circ} \mathrm{C}$, step time $1183 \mathrm{sec}$ (b) Thermal evolution at the end of the 6 th layer deposition in ${ }^{\circ} \mathrm{C}$ (step time $\left.=1345 \mathrm{sec}\right)$

Figure 4 depicts the crosssection at the center of the structure along the X-axis. The heat source at the two extreme positions in a layer is considered to analyse the thermal gradient in the base plate around the deposition. Figure 4 a represents the thermal source at the start of the deposition during the $6^{\text {th }}$ layer. Figure $4 \mathbf{b}$ is at the instance during the end of the $6^{\text {th }}$ layer deposition. The thermal contour plot shows a temperature gradient in the base plate along the $\mathrm{Y}$-axis away from the deposition when the thermal source was at the contour of the building structure. This closely agrees with in situ measurement at three locations. It is evident that the temperature gradient in the base around the deposition. 
Phase 3 is the cooling period after the thermal source was turned off. A large cooling rate of $0.112^{\circ} \mathrm{C} / \mathrm{sec}$ and $0.138^{\circ} \mathrm{C} / \mathrm{sec}$ was recorded at TC_1 and TC_BC respectively. This is the consequence of a large thermal gradient to the surrounding deposition chamber. The cooling rate at TC_2 was recorded at $0.074 \mathrm{C} / \mathrm{sec}$.

\subsection{Distortion history}

Distortion in the deposited structure was measured by comparing it with the reference model. Figure 5 (a) shows the cross-section at the centroid of the structure in the Z-X plane. The blank white region inside the base plate represents the reference model inserted into the deposited structure model. Vertical distortion in the symmetric base plate can be seen maximum at the center. A large temperature at the deposition interface on the base plate results in volumetric expansion. Linear expansion of material can be expected from stable austenitic steel $316 \mathrm{~L}$ that doesn't undergo phase transformation. Thermal dilatation could be resisted by base plate material around the deposition due to the thermal gradient discussed in the previous section. The comparatively large temperature below deposition in the base plate aid vertically downward distortion as shown in (Figure 5 a).

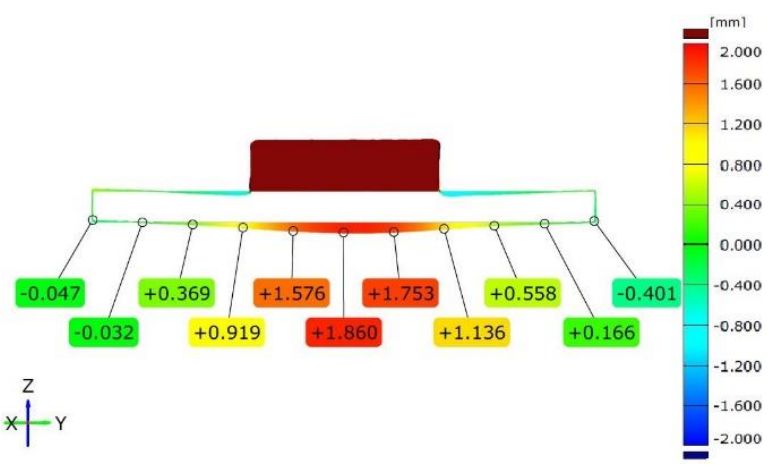

(a)

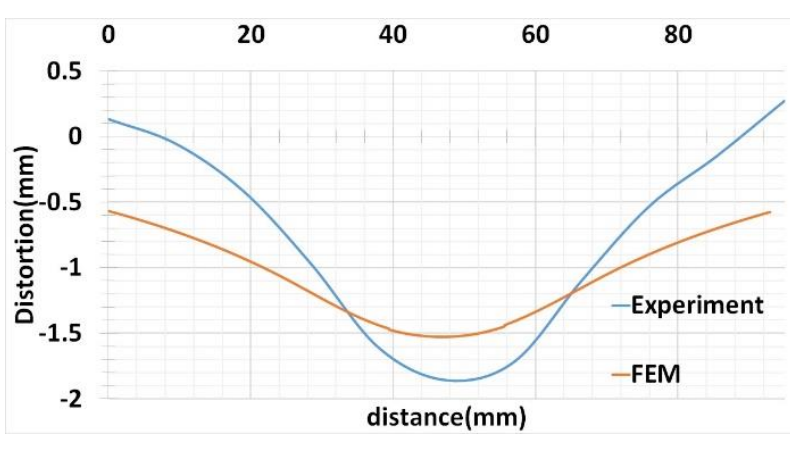

(b)

Figure 5 (a) Distortion measurement in Z-X plane (b) Distortion comparison graph

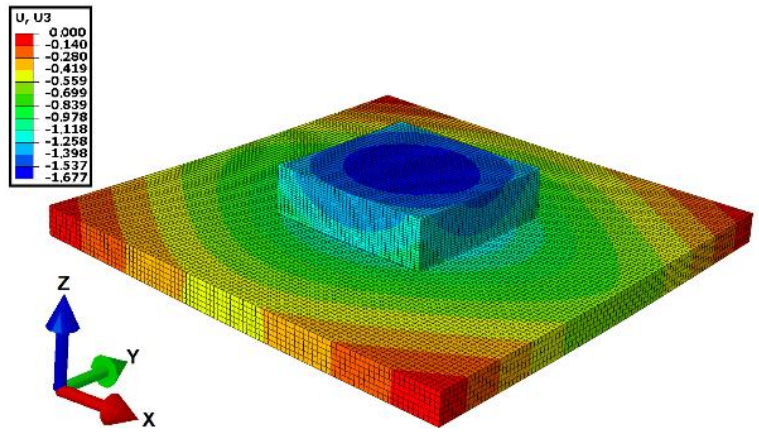

(a)

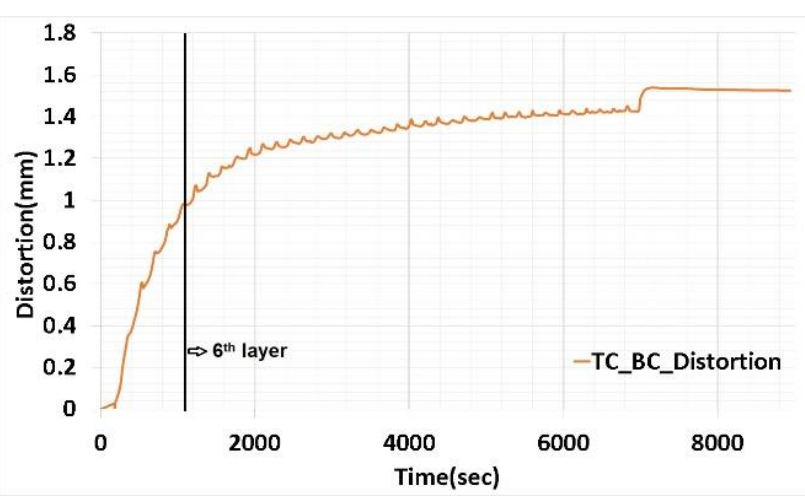

(b)

Figure 6 (a) Vertical distortion contour plot in $\mathrm{mm}$ (b) Nodal distortion at the bottom center of the base plate

Numerical results for distortion agree trend with the experiment measurement depicted in (Figure $5 \mathbf{b}$ ). The distortion curve is an average between two plane from $Z X$ axis and $Z Y$ axis. The vertical distortion contour plot from FEM simulation is depicted in (Figure 6 a). Distortion history from the FEM model is classified into 3 phases according to the distortion rate. The node at the bottom center of the base plate surface which experiences maximum distortion is considered for analysis shown in (Figure $\mathbf{6} \mathbf{b}$ ). The deposition until the 6th layer is classified as the first phase of distortion which contributes a significate amount of $62 \%$ for total distortion. The distortion per layer deposition was at a larger magnitude in this section. The first phase distortion 
can be mitigated by reducing the temperature gradient in the base plate. One of the promising methods is base plate preheating [4]. The second phase of distortion is from the sixth layer onwards to the end of the deposition. It accounts for $29 \%$ to total distortion. The process parameter plays an important role in mitigating distortion in the second phase [4]. The process parameter varying could affect the mechanical properties of the built structure. The third phase of distortion belongs to the cooling period. It accounts for $9 \%$ of the total distortion of the structure. One possible option to mitigate distortion in this phase is by reducing the cooling rate.

\section{CONCLUSION}

The symmetric base plate was selected to study distortion during the deposition process. The symmetric base plate was explicitly chosen to avoid longitudinal bending, buckling distortion, rotational distortion, etc from a concentric thermal source. A large distortion beneath the deposition area noticed due to the thermal gradient in the base plate. The numerical model was built for thermo-mechanical simulation and calibrated to experimental results. The thermal gradient inside the base plate was studied from the thermal numerical model. The distortion rate during the deposition process was classified using the numerical model. The validated model provides a modeling framework for DED simulation to implement proposed distortion techniques at various stages during the deposition process.

\section{ACKNOWLEDGEMENTS}

The paper was developed with a support from the ERDF project Pre-Application Research of Functionally Graduated Materials by Additive Technologies, No. CZ.02.1.01/0.0/0.0/17_048/0007350.

\section{REFERENCES}

[1] DASS, A. \& MORIDI, A. State of the art in directed energy deposition: From additive manufacturing to materials design. Coatings. 2019, vol. 9, pp. 418.

[2] JENDRZEJEWSKI, R., ŚLIWIŃSKI, G., KRAWCZUK, M. \& OSTACHOWICZ, W. Temperature and stress fields induced during laser cladding. Comput. Struct. 2004, vol. 82, pp. 653-658 .

[3] AGGARANGSI, P. \& BEUTH, J. L. Localized preheating approaches for reducing residual stress in additive manufacturing. 17th Solid Free. Fabr. Symp. SFF, 2006, pp. 709-720.

[4] LU, X. et al. Residual stress and distortion of rectangular and S-shaped Ti-6Al-4V parts by Directed Energy Deposition: Modelling and experimental calibration. Addit. Manuf., 2019, vol. 26, pp. 166-179.

[5] DENLINGER, E. R. \& MICHALERIS, P. Effect of stress relaxation on distortion in additive manufacturing process modeling. Addit. Manuf., 2016, vol. 12, pp. 51-59.

[6] CORBIN, D. J., NASSAR, A. R., REUTZEL, E. W., BEESE, A. M. \& MICHALERIS, P. Effect of substrate thickness and preheating on the distortion of laser deposited ti-6al-4v. J. Manuf.Sci.Eng. Trans. ASME, 2018, vol. 140, pp 1-9.

[7] DING, C., CUI, X., JIAO, J. \& ZHU, P. Effects of substrate preheating temperatures on the microstructure, properties, and residual stress of $12 \mathrm{CrNi2}$ prepared by laser cladding deposition technique. Materials (Basel), 2018, vol. 11.

[8] KIRAN, A., HODEK, J., VAVŘíK, J., URBÁNEK, M. \& DŽUGAN, J. Numerical simulation development and computational optimization for Directed Energy Deposition Additive Manufacturing process. Materials, 2020.(under review) 